\title{
Agreement in Archi: an LFG Perspective ${ }^{1}$ \\ Louisa Sadler (University of Essex)
}

\section{Introduction}

This chapter will approach a number of aspects of syntactic agreement in Archi from the perspective of LFG: by syntactic agreement I refer to agreement phenomena which rely, partly or wholy, on information expressed at a syntactic level of representation. In this section I provide a brief sketch of relevant aspects of the framework.

LFG is a constraint-based theory of generative grammar with a strong architectural commitment to accommodating the breadth of variation seen across languages (for a comprehensive introduction see Bresnan (2001); Dalrymple (2001)). At the core of the formalism is the notion of correspondence between distinct, simultaneously present structures modelling different kinds of linguistic information. Rather than modelling distinct types of linguistic information by means of one common data structure, LFG posits different gramatical structures, with distinct primitives and formal descriptions. Representations at each level are motivated by factors internal to that level, and the model of syntax observes lexical integrity and monotonicity. The separate structures are related by correspondence or mapping functions. The principle syntactic structures are c-structure and f-structure, which model surface constituency and syntactic predicate-argument relations respectively. The mapping function $\phi$ places elements of c-structure in correspondence with elements of f-structure.

C-structures are represented as simple phrase structure trees which model dominance and precedence relations, with complete fully inflected words as the leaves of the tree. LFG c-structure accommodates a range of different phrase structure models for configurational and non-configurational constructions. In terms of notation, LFG phrase structure rules support regular expressions, including Kleene star and Kleene plus (denoting zero or more and one or more repetitions of the category at hand, respectively).

F-structures model syntactic predicate -argument relations and functional relations such as subject annd object, local and non-local dependencies, and other morphosyntactic information, abstracting away from many aspects of external form. Formally, f-structures are finite (many-to-one) functions from attributes to values. (1) provides an illustration of the two levels, and shows the $\phi$ mapping between them.

\footnotetext{
${ }^{1}$ I am grateful to Oliver Bond, Bob Borsley, Dunstan Brown, Grev Corbett, Mary Dalrymple, Masha Polinsky, Peter Sells and other attendees at the Archi seminars for comments and feedback and helpful discussion, and to the reviewers for this volume. I am especially grateful to Marina Chumakina for her patience and good humour in the face of many requests for further data and clarification.
} 
(1) Kim snores

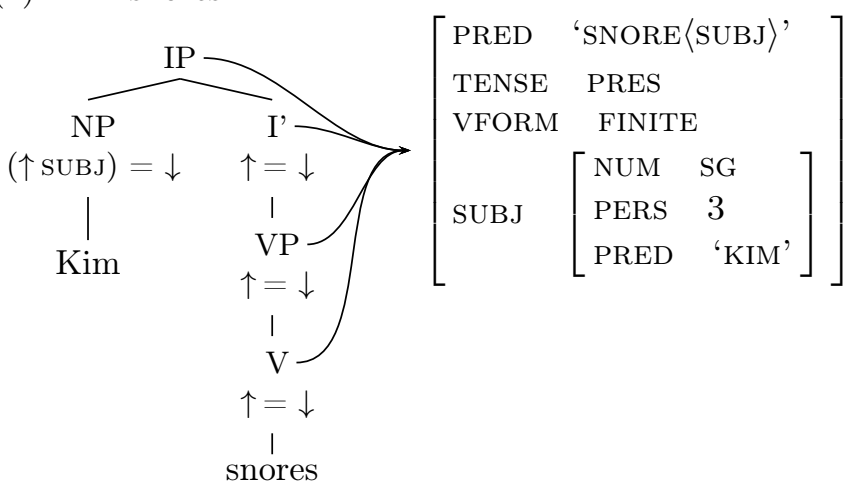

The symbol $\downarrow$ in the annotations to the nodes in (1) denotes the f-structure which corresponds to the node with which this symbol is associated and $\uparrow$ denotes the f-structure of the mother of this node. Thus $\uparrow=\downarrow$ says that the f-structure of the mother node is equal to the f-structure of the current node ('my mother's f-structure is my f-structure') and the annotation ( $\uparrow$ SUBJ) $=\downarrow$ in (1) specifies that the f-structure of the NP is the value of the SUBJ attribute in the f-structure of the IP. The value of the feature PRED plays a special role: it is a semantic form specifying the thematic arguments subcategorised by the predicate snore. Well-formedness principles of completeness and coherence apply to regulate the distribution of the governable grammatical functions ( $\mathrm{SUBJ}, \mathrm{OBJ}, \mathrm{OBJ}_{\theta}, \mathrm{OBL}_{\theta}$, COMP, XCOMP) in f-structures.

Syntactic agreement (that is, syntactially mediated covariation in form) is primarily modelled as co-specification of agreement features at the level of $f$ structure, which represents abstract grammatical relations and their properties, rather than at the level of c-structure, concerned with constituency and notions of dominance and precedence. This is a contingent fact and not a requirement of the formalism PER SE. It is important to see that LFG's s projection architecture also accommodates the statement of agreement at other levels of representation (for example, at m-structure Belyaev (2013) or g-structure, modelling grammatical marking Falk (2006a)). While many agreement relations refer solely to f-structure notions, others may also refer to or depend on further constraints at other levels of representation and so call for a multi-dimensional approach involving argument-structure (notions of thematic prominence), information structure (notions such as discourse TOPIC and FOCUs (Dalrymple and Nikolaeva, 2011)) or linear and c-structure relations, for example in the treatment of single conjunct agreement (Sadler, 1999; Kuhn and Sadler, 2007; Dalrymple and Hristov, 2010)).

In general terms, the approach to syntactic agreement in LFG is symmetric rather than directional. That is, full or partial agreement information can be provided by either or both/all of the target(s) and controller. Items which do not fully 
specify their agreement features simply lack full specification. Both major subtypes of syntactic agreement, predicate-argument agreement and head-modifier agreement, are normally modelled as co-specification of a single set of features expressed in the f-structure of the controller, rather than as feature sharing between controller and target(s). Thus agreement features are represented in the f-structure of the controller (which they express intrinsic properties of), rather than as part of the f-structure of each target on which they are realised. For example the lexical entry of snore relevant to (1) contains the information shown in (2), in which the target co-specifies features of the sUBJ controller. As before, the symbol $\uparrow$ means 'the f-structure of my mother' and hence here denotes the f-structure of the $\mathrm{V}$ node.

(2) snores ( $(\uparrow$ PRED $)=$ 'snore $<$ SUBJ $>$ '

$(\uparrow \mathrm{VFORM})=$ FINITE

$(\uparrow$ TENSE $)=$ PRES

$(\uparrow$ SUBJ PERS $)=3$

$(\uparrow \mathrm{SUBJ}$ NUM $)=\mathrm{SG}$

Head-modifier agreement often corresponds to a relation between an element and the f-structure of the phrase which 'contains' it. Consider a case of definiteness (DEF) agreement in Swedish discussed in Borjars and Payne (2013, $157)$, in relation to the example in (3). The modifying adjective specifies information about the containing nominal f-structure, that is, the f-structure of the nominal of which it is an ADJunct. This f-structure is shown in (4) and labelled $n$ : for convenience. The f-structure of the adjective is labelled $a$ : note that the $\mathrm{ADJ}$ (unct) is a set-valued feature in LFG, hence the \{\} brackets in the representation.

(3) den stora boken DEF big.DEF book.DEF

the big book

Swedish

(4)

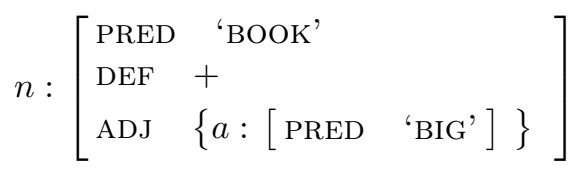

The lexical entry for the agreeing adjective is shown in (5), and specifies that the DEF feature must have the value + in the f-structure (here $n$ ) which is reached by following the attribute path $\mathrm{ADJ} \in$ from the f-structure of the adjective itself $(a$ in $(4))$.

(5) $\operatorname{stora} \quad(\uparrow$ PRED $)=$ 'big'

$$
((\operatorname{ADJ} \in \uparrow) \mathrm{DEF})={ }_{c}+
$$


The statement $((\operatorname{ADJ} \in \uparrow) \mathrm{DEF})={ }_{c}+$ uses an inside-out expression to refer to an f-structure whose value for the attribute path ADJ $\in$ is the f-structure $\uparrow$. The lexical entry also illustrates the use of a constraining equation (as opposed to a defining equation) which does not define an attribute-value pair but can only be satisfied by f-structures in which the attribute-value pair is defined (by some other equation).

\subsection{Hybrid Behaviour}

Several phenomena suggest that syntactic agreement makes reference to (at least) two distinct sets of syntactic agreement features, known as INDEX and CONCORD in the LFG context (King and Dalrymple, 2004) (we have abstracted away from this in the previous section $)^{2}$ These phenomena include agreement with hybrid nouns, an example of which is given in $(6),{ }^{3}$ and agreement with coordinate stuctures. In (6) we see that the hybrid noun deca 'children' controls FSG agreement within the NP but NPL agreement within the sentential domain.

(6) Ta dobr-a deca su doš-l-a.

that.FSG good-FSG children AUX.3PL come.PPRT-NPL

Those good children came. Serbian/Croatian, Wechsler and Zlatić (2003, 38)

In (7) we see that the determiner this shows SG agreement with boy and girl and yet the NP as a whole controls PL agreement on the verb have.

(7) This boy and girl have become skilled at setting the places for their classmates at snacktime.

(http://www.edvid.com/infant.asp)

The essence of the LFG approach to this phenomenon is shown representationally in (8) (from King and Dalrymple (2004)). Coordinate structures are represented as sets at f-structure: the f-structure corresponding to this boy and girl shown in (8) is a set containing two features (SPEC and INDEX) and two members (within the curly brackets) - the f-structures of 'boy' and 'girl' respectively. Two distinct sets of syntactic agreement features (INDEX and CONCORD) are postulated, where INDEX is a non-distributive feature (that is, it does not distribute into set-valued features (see (9)) and CONCORD is a distributive feature. ${ }^{4}$ The determiner this constrains the CONCORD NUM value of the f-structure's of boy and

\footnotetext{
${ }^{2}$ A similar, but not identical, distinction is posited in HPSG, see Wechsler and Zlatić (2000, 2003).

${ }^{3}$ For recent discussion of hybrid nouns, see Hristov (2013). For consistency with their work, we follow the practice of Wechsler and Zlatić (2003) (from whom this example is borrowed) in referring to the language in question as Serbian/Croatian, although a reviewer suggests a more correct labelling might be Serbian or Serbo-Croat.

${ }^{4}$ King and Dalrymple (2004) take this to place a CONCORD SG constraint, as shown in (8). A reviewer points to the existence of examples such as this house and outbuildings and this manager and players, which do not conform to the pattern discussed above. Other attested
} 
girl (the relevant values are shown boxed in (8)). It is very often the case that CONCORD NUM and GEND features control NP-internal agreement while INDEX features are relevant to predicate-argument agreement, but this is not always the case. For example, Bulgarian admits INDEX agreement NP internally as resolution is possible with conjoined controllers (Hristov, 2013, 348).

(8) this boy and girl

this: $(\uparrow$ CONCORD NUM $)=\mathrm{SG}$

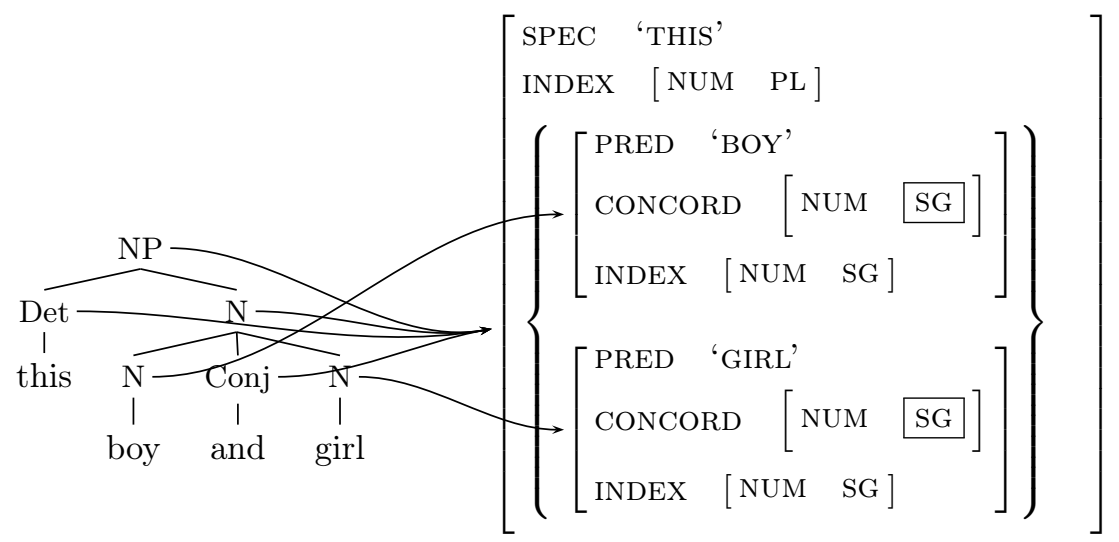

(9) For any distributive property $P$ and set $s, P(s)$ iff $\forall f \in$ s.P( $f)$.

For any nondistributive property $P$ and set $s, P(s)$ iff $P$ holds of $s$ itself. (Dalrymple and Kaplan, 2000)

In most cases, the values of the GEND and NUM attributes of INDEX and CONCORD for a element are identical. To avoid unnecessary complications and clutter we ignore this distinction in the discussion of most of the Archi data in what follows: the default assumption is that head-modifer agreement within NP is targetting CONCORD features and predicate argument agreement is targetting INDEX features.

\subsection{Expressing Lexical Generalisations}

Templates are used in LFG to capture relations between descriptions (not relations between representations). Templates are named functional descriptions, that is, named collections of equations. They may be organised into simple hierarchies which encode inclusion. It is important to note that templates are

examples of this type which I have found on the web include this house and grounds, this boat and sails, this judge and jurors and this mother and cubs. Examples such as these do not, however, have the flavour of accidental coordination (which is what King and Dalrymple (2004)'s proposal is intended to cover). Neither do they correspond straightforwardly to the sort of natural coordination discussed by Dalrymple and Nikolaeva (2006), and they generally appear to control plural INDEX agreement alongside the singular CONCORD. I leave these cases to one side here. 
straightforward abbreviatory devices and have no ontological status in the domain of linguistic objects in LFG. The use of templates is best explained by means of an example. Consider the lexical entry for (2) above. Much of the information in this lexical entry is shared with other lexical entries. This information can be factored out and expressed in templates, which are then called in the (revised) lexical entry. (Templates can also be called in c-structure rules, but we make no use of this here.) The following are possible template definitions:

$$
\begin{aligned}
\text { PRESENT }=\quad & (\uparrow \text { VFORM })=\text { FINITE } \\
& (\uparrow \text { TENSE })=\text { PRES } \\
\text { 3SG }=\quad & (\uparrow \text { SUBJ PERS })=3 \\
& (\uparrow \text { SUBJ NUM })=\mathrm{SG}
\end{aligned}
$$

It is also possible to define and use templates with parameters, where the value for the parameter can be provided in the lexical entry. For example, using FN to stand for the predicate name, we can define a subcategorisation template such as (10) for intransitive verbs: the predicate name itself will be supplied in the lexical entry, and serve as the value of the parameter.

$$
\text { (10) } \operatorname{INTRANSITIVE}(\mathbf{F N})=(\uparrow \mathrm{PRED})=\text { 'FN }<(\uparrow \mathrm{SUBJ})>\text { ' }
$$

These three templates can be used to simplify the lexical entry for snore:

$$
\begin{aligned}
\text { (11) snores } & @ \text { PRESENT } \\
& @ 3 \text { SG } \\
& \text { @INTRANSITIVE(SNORE) }
\end{aligned}
$$

We will make considerable use of templates to capture agreement generalisations in what follows. See Asudeh (2012) or Asudeh et al. (2008) for work in LFG making significant use of templates.

Given the current state of our knowledge concerning the syntax of Archi, the analysis put forward is necessarily exploratory in nature. As further syntactic information emerges, it will very likely be necessary to revisit many of the analytic details to provide a fragment grammar which approaches descriptive adequacy. Nonetheless the methodology adopted in this chapter is to provide as detailed and as specific an account as possible, rather than to outline the broad directions in which an account may be sought. It is hoped that with this level of formalisation, it is possible to see where one has gone wrong as additional facts emerge. As with other frameworks, analyses in a number of different styles may be expressed in LFG. Where there have been choice points of this sort, my general approach here has been to pursue the analytic paths which seem to me to be most radically LFG-like. I have made virtually no assumptions about the constituent structure of Archi. 


\section{Agreement in the Clausal Domain}

In Archi as in other languages, the core instance of agreement in the clause domain is that of predicate argument agreement, although there are a number of subsidiary agreement phenomena in which the clausal agreement controller is implicated, as in other Nakh-Daghestanian languages. Archi is an ergativeabsolutive language, and it is the absolutive argument which controls clausal agreement.

This agreement relation is sensitive to case, rather than to configuration, linear order or notions of information structure. While Nakh-Daghestanian languages, including Archi, show predominant dependent head word order and are basically SOV in the clausal domain (van den Berg, 2005, 171), word order is not totally rigid (for example, topical material may appear postverbally). The basic agreement relation remains invariant across the clause types. Intransitive verbs and non-verbal predicates take a single absolutive argument, and agree with it. The majority of transitive verbs show ergative absolutive alignment, and some show dative absolutive alignment: in each case, the verbal predicate shows agreement with the absolutive argument. ${ }^{5}$ Recall that the agreement features for predicate argument agreement are only NUM and GEND, and hence the overall system of predicate argument agreement is considerably simpler than those Nakh-Daghenstanian languages which have innovated some form of person agreement, and hence show distinct and only partially overlapping NG and PERS agreement systems (e.g Dargwa and Akhvakh; Creissels (2006); Belyaev (2013) - see in particular the latter for an account of competing controllers for different agreement features in Dargwa). Basic examples of agreement in clauses with verbal and non-verbal predicates (here a so-called attributive (see section 3 below) in predicative use) are shown in (12)-(16). We will adopt the practice of boxing the controller in the Archi data and indicating the agreement features on the target gloss in crucial examples (for example, on first presentation of a key agreement point).

(12) \begin{tabular}{|ll} 
buwa & d-aq ${ }^{\complement}$ a \\
mother(II)[SG.ABS] & II.sG-come.PFV
\end{tabular}

Mother came

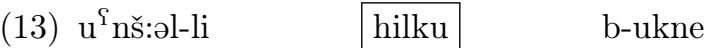
lizard(III)-SG.ERG fly(III)[SG.ABS] III.SG-eat.PFV

The lizard ate the fly.

(14) to-w-mi-s Ajša d-ak:u that.one-I.SG-OBL.SG-DAT Aisha(II)[SG.ABS] II.SG-See.PFV

\footnotetext{
${ }^{5}$ For the purposes of this paper, I will simply assume that a simple CASE feature is relevant to f-structure and associate case defining equations with the lexical elements. This is the most vanilla set of assumptions to make.
} 
He has seen Aisha

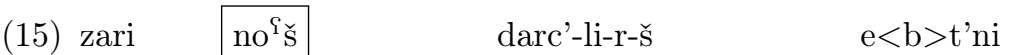
1SG.ERG horse(III)[SG.ABS] post-OBL.SG-CONT-ALL (III.SG)tie.PFV

I tied the horse to the post

(16)
axbəzan
$n a^{\mathrm{i}} 3-\mathrm{du}-\mathrm{b}$
$\mathrm{e}<\mathrm{b}>\mathrm{di}$
apricot(III)[SG.ABS] be.unripe-ATTR-III.SG $<$ III.SG $>$ be.PST

The apricot was unripe.

Bond \& Chumakina, this volume, chap. 2

\subsection{Morphological or Syntactic Ergativity}

We use the term ergative language to refer to languages which show an ergativeabsolutive alignment pattern. In such languages the single core argument of an intransitive predicate (denoted $\mathrm{S}$ ) is marked with absolutive case, as is the lower core argument (denoted $\mathrm{P}$ ) of a transitive predicate. The higher core argument (or A) of a typical transitive predicate is marked with ergative case. It is commonplace to distinguish two subtypes of ergative language. In a morphologically ergative language the obliqueness ordering of grammatical relations (SUBJ $>$ OBJ) in the basic verbal voice matches the obliquesness ordering at argument structure, but case marking does not reflect the obliqueness ordering of grammatical functions. In a syntactically ergative language the obliqueness ordering of grammatical relations in the basic verbal voice does not match the obliquesness ordering at argument structure but involves an inverse mapping (for discussion of syntactic ergativity in an LFG context see Arka and Manning (1998); Manning (1996); Falk (2006b)). This difference is represented schematically in (17).

\begin{tabular}{|l||ccc|}
\hline & A (Arg1 Trans) & S (Arg1 Intrans) & P (Arg2 Trans) \\
\hline MorPH ERG & SUBJ & SUBJ & OBJ \\
\hline & ERG & ABS & ABS \\
\hline SYN ERG & OBJ & SUBJ & SUBJ \\
\hline
\end{tabular}

The question is whether the absolutive argument corresponds to the most prominent surface grammatical function or not? The consensus of the great majority of work on the Nakh-Daghestanian languages is that ergativity is essentially a morphological phenomenon in these languages. ${ }^{6}$ For example, the broad picture which emerges from the overview survey in Forker (to appear) is that that GEND/NUM agreement (and person agreement in Lak) and CASE assignment are (syntactically) ergative while other constructions, including relativisation,

\footnotetext{
${ }^{6}$ But see Nichols (2008) on Ingush for a different view of that language. For a recent contribution applying a battery of syntactic alignment tests to a group of Tsezic languages see Comrie et al. (2013).
} 
imperatives, reflexivisation and reciprocalisation, control constructions and conjunction reduction either give neutral results or are accusative in alignment. It seems that evidence from other syntactic phenomena in Archi supports the view that grammatical functions are relevant to the statement of syntactic generalisations in this language. For example, the ABS reflexive in (18) takes the ERG co-argument as antecedent in (18). In (19) the DAT (SUBJ) is antecedent for the ABS reflexive co-argument, while the reverse is ungrammatical, as shown in in $(20) .^{7}$

(18) Pat'imat-li inž- $\mathrm{a}<\mathrm{r}>\mathrm{u}$ čučebo. Patimat(II)-SG.ERG LOG.SG.ABS-PCL $<$ II.SG $>$ wash.PFV Patimat washed herself.

(19) laha-s

inž-aw w-ak:u $\operatorname{lad}(\mathrm{I})$. .SG.OBL-DAT LOG.SG.ABS-I.SG I.SG-See.PFV A boy saw himself.
(20) *žu-s:-aw
lo
w-ak:u.

LOG.SG-DAT-I.SG lad(I)[SG.ABS] I.SG-See.PFV

Intended: A boy saw himself.

We tentatively conclude, therefore, that Archi does not exhibit inverse mapping although NUM-GEND agreement is syntactically ergative in the sense that it is controlled by the $(\mathrm{S} / \mathrm{P})$ ABS argument. We do not rule out the possibility that some other phenomena also involve syntactic ergativity. Abstracting away from less relevant details, we take the f-structure of a sentence such as (21) to be as shown in (22).

(21) Juq'up-li

moč'or $\chi:$ artbo Jaqub(I)-SG.ERG beard(III)[SG.ABS] shave.PFV Jaqub shaved (off) (his) beard.

$$
\left[\begin{array}{lll}
\text { PRED } & \text { 'SHAVE }\langle\text { SUBJ, OBJ }\rangle \\
\text { OBJ } & {\left[\begin{array}{ll}
\text { PRED } & \text { 'BEARD' } \\
\text { NUM } & \text { SG } \\
\text { GEND } & \text { III } \\
\text { CASE } & \text { ABS }
\end{array}\right]} \\
\text { SUBJ } & {\left[\begin{array}{ll}
\text { PRED } & \text { 'JAQUB' } \\
\text { NUM } & \text { SG } \\
\text { PERS } & 3 \\
\text { GEND } & \text { I } \\
\text { CASE } & \text { ERG }
\end{array}\right]}
\end{array}\right]
$$

\footnotetext{
${ }^{7}$ We should note however, that reversals appears to be possible in some cases.
} 


\section{$2.2 \quad$ Stating Agreement Constraints}

The basic agreement generalisation of Archi for agreement with a clausal argument is very simple: targets agree in NUM and GEND with the (clausal) agreement controller, the absolutive argument. To capture this fact we first define the basic agreement information in terms of simple parametrised templates (as introduced in section 1.2. above) along the lines shown in (23). The I.SG template specifies that the argument which is the value of its parameter has the value I for its GEND feature and the value SG for its NUM feature.

$$
\begin{array}{llll}
\mathbf{I . S G}(\mathbf{P}) \equiv & \begin{array}{l}
(\mathrm{P} \text { GEND })=\mathrm{I} \\
(\mathrm{P} \text { NUM })=\mathrm{SG}
\end{array} & \mathbf{I I I . S G}(\mathbf{P}) \equiv \begin{array}{l}
(\mathrm{P} \text { GEND })=\mathrm{III} \\
(\mathrm{P} \text { NUM })=\mathrm{SG}
\end{array} \\
\mathbf{I I . S G}(\mathbf{P}) \equiv \begin{array}{l}
\text { (P GEND })=\mathrm{II} \\
(\mathrm{P} \text { NUM })=\mathrm{SG}
\end{array} & \mathbf{I V . S G}(\mathbf{P}) \equiv \begin{array}{l}
(\mathrm{P} \text { GEND })=\mathrm{IV} \\
(\mathrm{P} \text { NUM })=\mathrm{SG}
\end{array}
\end{array}
$$

To express the basic subcategorisation and case assignment patterns of subcategories of predicates we might define a template hierarchy along the lines shown in (24). A selection of template definitions are shown in (25)-(28).

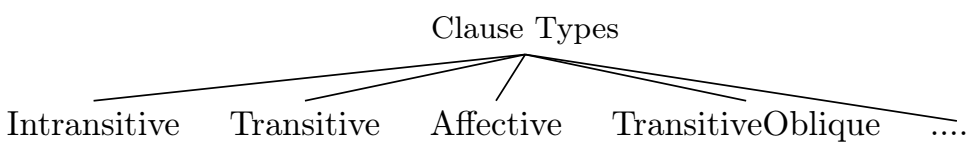

(25) $\operatorname{TransitiVe}(\mathbf{F N}) \equiv(\uparrow \mathrm{PRED})=$ 'FN $<$ SUBJ, OBJ $>$ '

$(\uparrow$ SUBJ CASE $)=$ ERG

$(\uparrow$ OBJ CASE $)=\mathrm{ABS}$

(26) $\operatorname{INTRANSITIVE}(\mathbf{F N}) \equiv(\uparrow \operatorname{PRED})={ }^{\prime} \mathrm{FN}<\mathrm{SUBJ}>$ '

$(\uparrow$ SUBJ CASE $)=$ ABS

(27) $\operatorname{AFFECTIVE}(\mathbf{F N}) \equiv(\uparrow \mathrm{PRED})=$ 'FN $<$ SUBJ, OBJ $>$ '

$(\uparrow$ SUBJ CASE $)=$ DAT

$(\uparrow$ OBJ CASE $)=\mathrm{ABS}$

(28) TRANSITIVEOBLIQUE $(\mathbf{F N}) \equiv(\uparrow$ PRED $)=$ 'FN $<$ SUBJ, OBJ, OBL $>$ '

$(\uparrow$ SUBJ CASE $)=$ ERG

$(\uparrow$ OBJ CASE $)=$ ABS

With templates along these lines defined, the lexical description of the intransitive verb which occurs in (12) is shown in (29). (30) is the (relevant part of) the lexical description for the transitive verb used in (13) while (31) gives the description for the affective verb exemplified in (14). 
(29) $d-a q^{\complement} a \quad(\uparrow \mathrm{ASP})=\mathrm{PFV}$

$$
\text { @intransitive(COME) }
$$

@II.SG(个 SUBJ)

(30) b-ukne

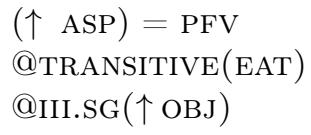

(31) d-ak:u

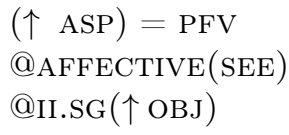

Consider the example (13) repeated here as (32), for which the f-structure is shown in (33): the agreement information associated with the lexical verb is shown in bold in the f-structure of the OBJ. The verb calls the TRANSITIVE template with the parameter value EAT and the III.SG template with the parameter value $\uparrow$ OBJ. The information that the succinct lexical entry in (30) expresses is given in the verbose lexical entry in (34) (after template expansion).

(32) $\mathrm{u}^{\mathrm{S}}$ nš:əl-li hilku b-ukne lizard(III)SG.ERG fly(III)[SG.ABS] III.sG-eat.PFV

The lizard ate the fly.

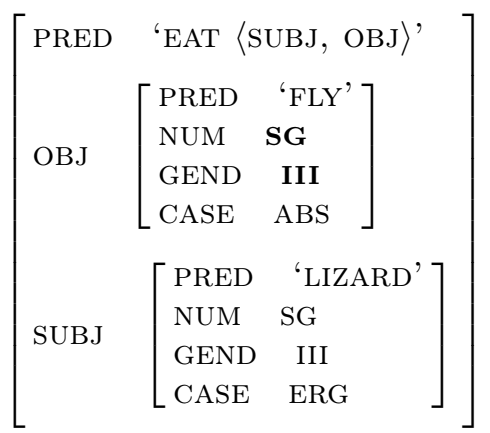

(34) b-ukne $(\uparrow \mathrm{ASP})=\mathrm{PFV}$

$(\uparrow \mathrm{PRED})=$ 'EAT $<\mathrm{SUBJ}, \mathrm{OBJ}>$ '

$(\uparrow$ SUBJ CASE $)=$ ERG

$(\uparrow$ OBJ CASE $)=$ ABS

$(\uparrow$ OBJ GEND $)=$ III

$(\uparrow$ OBJ NUM $)=$ SG

All things being equal, the prediction of an f-structure-based account of syntactic agreement is that agreement controllers do not necessarily have to be overt in 
the c-structure of the clause where they control agreement. An example might be the adjunct clause in (35), and other circumstances might involve agreement with fillers in unbounded dependency constructions.

(35) jamu-m porma-li-t $\quad a<r>\chi u-l i$,

this-III.SG form(III)-SG.OBL-SUP lie.down $<$ II.SG $>$.PFV.CVB

$\mathrm{e}<\mathrm{r}>\chi: \mathrm{u} \quad$ zon

remain $<$ II.SG $>$.PFV 1SG.ABS

Having lain down in this way, I stayed (there) (woman speaking).

In relation to (35), the lexical description of the converb which is head of the adjunct clause will introduce an optional pronominal argument, with which it agrees, in the structure shown in (36). ${ }^{8}$

$$
\left[\begin{array}{cl}
\text { SUBJ } & \text { 'REMAIN }<\text { SUBJ>' } \\
& {\left[\begin{array}{ll}
\text { PRED } & \text { 'PRO' } \\
\text { CASE } & \text { ABS } \\
\text { NUM } & \text { SG } \\
\text { PERS } & 1
\end{array}\right]} \\
\text { ADJ } & \left\{\left[\begin{array}{ll}
\text { PRED } & \text { 'LIE. DOWN }<\text { SUBJ>' } \\
\text { SUBJ } & {\left[\begin{array}{ll}
\text { PRED } & \text { 'PRO' } \\
\text { CASE } & \text { ABS } \\
\text { NUM } & \text { SG } \\
\text { GEND } & \text { II }
\end{array}\right]} \\
\text { ADJ } & \left\{\left[\begin{array}{ll}
\text { PRED } & \text { 'FORM' } \\
\text { CASE } & \text { SUP } \\
\text { GEND } & \text { III } \\
\text { NUM } & \text { SG }
\end{array}\right]\right\}
\end{array}\right]\right\}
\end{array}\right.
$$

\section{$2.3 \quad$ Using Pivot}

In the approach outlined so far, the agreement controller is directly identified as corresponding to one of the direct terms SUBJ or OBJ in the subcategorisation templates along the lines of those shown in (25)-(28). An alternative is to adopt the notion of PIVOT within an LFG setting (Falk, 2006b). In a study of notions of subjecthood and ergativity, Falk (2006b) proposes the use of a syntactic PIVOT attribute in f-structure representations, with language-specific assignment. The fundamental idea is that in NOM-ACC languages PIV is identified with $\widehat{G F}$ (the highest function, that is, the SUBJ). In cases of syntactic ergativity, however, it

\footnotetext{
${ }^{8}$ For concreteness, we assume that this is an example of anaphoric control, in LFG terms. If it should turn out to involve functional control into an adjunct, then the analysis would be slightly different, but again, no null c-structure node would be postulated.
} 
denotes $\widehat{\mathrm{GF}}$ of intransitives and OBJ of transitives. In a language which is fully syntactically ergative, in which the mapping to grammatical functions is inverse, constraints in Falk's 2006b system require that many types of constraints make reference to PIV rather than other GFs. In recent work, Belyaev (2013) expresses NUM-GEND agreement in Dargwa using PIV (and thus essentially captures the notion that this agreement phenomenon in Dargwa is syntactically ergative). Although the use of an additional PIV function does introduce some additional 'clutter' into f-structure (and thus representationally is perhaps more in the spirit of HPSG than LFG), it does offer a convenient handle for the statement of agreement generalisations, and may be a reasonable (representational) move, especially if some other constructions are found to reflect a syntactically ergative organisation. ${ }^{9}$ The alteration to what we have proposed so far is small: agreement constraints are stated over PIV, which is always token-identical with the absolutive argument, rather than directly over SUBJ or OBJ. Illustrative lexical entries are shown in (37) and (38) and the f-structure for (32) in (39). The grammar as a whole identifies the pivot with the absolutive argument (SUBJ of intransitives and OBJ of transitives, affectives and transitive oblique clauses). Falk (2006b) replaces the use of SUBJ in f-structures with $\widehat{\mathrm{GF}}$, but for ease of exposition we retain SUBJ as the label for this non-object, direct term function.

$$
\begin{aligned}
& d-a q^{\complement} a \quad(\uparrow \mathrm{ASP})=\mathrm{PFV} \\
& \text { @intransitive(COME) } \\
& \text { @II.SG( } \uparrow \text { PIV) } \\
& \text { @TRANSITIVE(EAT) } \\
& \text { @III.SG(个 PIV) }
\end{aligned}
$$

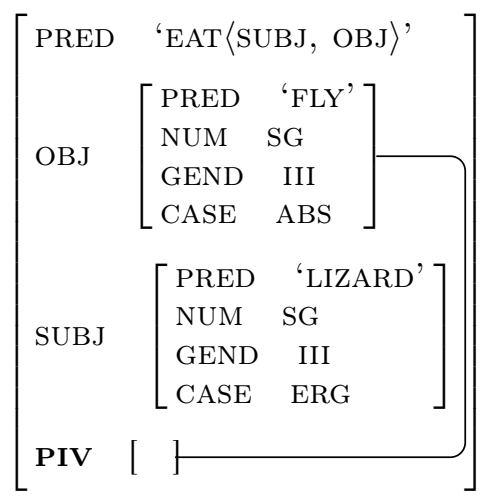

\footnotetext{
${ }^{9}$ Given the projection architecture of LFG it would be possible to represent PIV in a parallel dimension, but we do not explore that possibility here.
} 


\subsection{Other Agreement Targets}

We now turn to the phenomenon of agreement with the clausal agreement controller being realized on a range of other dependents. Recall that these unexpected agreement targets include a number of first person pronominal forms, some adverbial elements, an emphatic particle and one postposition. A striking aspect of this phenomenon is of course the degree to which it is specific to certain lexemes and indeed even certain cells of the pronominal paradigm. This argues strongly in favour of a lexical and form-driven approach, avoiding the need to invest elements which never show agreement with syntactic agreement features which are never realised. Among the agreeing pronouns are the ergative and genitive first person inclusive and the dative first person forms, illustrated in (40) and (41) respectively. The contrasting sentences in (41) show how the phenomenon is limited to part of the pronominal paradigm. ${ }^{10}$

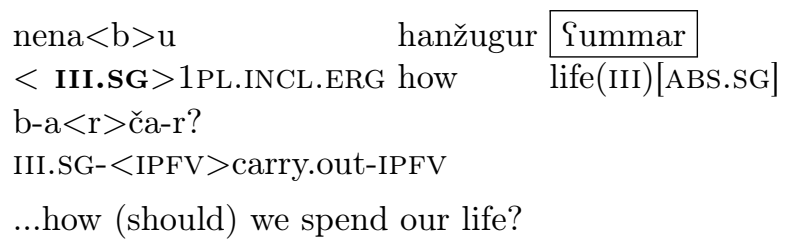

(41) a. was maq'sud w-ak:u-li hu-ra i $<$ w $>$ di you.DAT maqsud I.SG-See.PFV-CVB yes-QUEST $<$ I.SG $>$ be.PST

Have you seen Maqsud? Really?

(The speaker thinks it surprising)

$$
\begin{array}{llll}
\text { b. w-ak:u-li } & \text { w-ez } & \mathrm{i}<\mathrm{w}>\text { di } & \text { maq'sud } \\
\text { I.SG-See.PFV-CVB } & \text { I.SG-1SG.DAT }<\text { I.SG }>\text { be.PST maqsud }
\end{array}
$$

I have seen Maqsud.

(Chumakina, 2012, 33-34)

An important aspect of this phenomenon is that agreement will be realised on the pronominal form irrespective of its own grammatical function and role in the clause. In (41b) it was the dative subject. In (42) the agreement target is the benefactive OBL and the controller is the absolutive OBJ argument. An example such as (42) might suggest a possible analysis in terms of secondary predication (treating the dative marker as introducing a two place predicate). However, examples such as (41b) highlight the implausibility of such an approach to (idiosyncratic) pronominal agreement: to account for (41b) as secondary predication one would have to maintain that a seeing event introduces a secondary predication but it is entirely unclear what the semantic grounds for doing so

\footnotetext{
${ }^{10}$ Chumakina (2012) observes that in neutral contexts, the copula and converb would be adjacent and that their separation in (41) results in a special pragmatic effect. This is orthogonal to our concerns here.
} 
would be (or what the secondary predicate itself might be!). Furthermore, the question would arise as to whether examples without overt agreement on the dative argument would also involve an (entirely invisible) secondary predication. $^{11}$

(43) shows that the controller does not have to correspond to a c-structure constituent: the absolutive argument is not expressed as a separate pronoun, but still controls agreement. This is unproblematic for an account based on f-structure relations, because such an account does not make reference to cstructure.

$$
\begin{aligned}
& \begin{array}{lll}
\text { to-r-mi } & b-e z & a<b>u
\end{array} \\
& \text { that.one-II.SG-ERG III.SG-1SG.DAT dress(III)[SG.ABS] }<\text { III.SG }>\text { make.PFV }
\end{aligned}
$$

She made a dress for me.

(43) d-ez

$$
\text { zir } \mathrm{d}-\mathrm{e}<\mathrm{r}>\mathrm{q}^{\mathrm{S}} \mathrm{a}-\mathrm{r}-\mathrm{s} \mathrm{i}
$$

\section{II.SG-1SG.DAT behind II.SG- $<$ IPFV $>$ go-IPFV-CVB II.SG-be.PRS}

She goes after me (male speaking).

A plausible lexically-based approach to this phenomenon in LFG simply involves associating the appropriate agreement constraints with those pronouns which show agreement. Thus the lexical entry of the 1SG.DAT pronoun might specify constraints over the absolutive argument (that is, PIV) of its clause, using an inside-out statement, as shown in (44), where GF may be understood as ranging over a number of grammatical function (for example, it corresponds to SUBJ in (41b) and (43), and OBL in (42)). Recall that inside-out statements allow an element to define or constrain attributes of an f-structure which contains that element (see the introductory discussion of (5) above. The value of the parameter for the agreement template is thus the PIV attribute of the clause containing the dative argument. As an alternative, the same generalisation may be stated more verbosely in an analysis which eschews PIV, in the form shown in (45), where GFTERM should be understood as ranging over SUBJ and OBJ. The f-description uses the local name \%AGRC to pick out the absolutive argument, and then provides this attribute as the value of the parameter to the agreement template. In what follows, we will assume the more succinct, PIV-based treatment of (clausal) agreement constraints.

$$
\begin{aligned}
(44) b-e z \quad & (\uparrow \mathrm{PRED})={ }^{\prime} \mathrm{PRO} ' \\
& (\uparrow \mathrm{NUM})=\mathrm{SG} \\
& (\uparrow \mathrm{PERS})=1 \\
& (\uparrow \text { CASE })=\mathrm{DAT} \\
& \text { @ III.SG }((\text { GF } \uparrow) \text { PIV })
\end{aligned}
$$

\footnotetext{
${ }^{11}$ This is not to say, of course, that an account in terms of secondary predication is necessarily excluded in other cases. It may be motivated in some cases of adverbial agreement with the clausal absolutive, for example.
} 
(45) $b-e z$

$$
\begin{aligned}
& (\uparrow \mathrm{PRED})=\text { 'PRO' } \\
& (\uparrow \mathrm{NUM})=\mathrm{SG} \\
& (\uparrow \mathrm{PERS})=1 \\
& (\uparrow \mathrm{CASE})=\mathrm{DAT} \\
& ((\text { GF } \uparrow) \text { GFTERM })=\% \text { AGRC } \\
& (\% \text { AGRC CASE })=\text { ABS } \\
& \text { @ III.SG(\% AGRC) }
\end{aligned}
$$

Before leaving the issue of pronouns showing agreement with the absolutive, we note that a slight extension to the path given to the parameter will account for a fuller range of examples in addition to those discussed so far. (46) shows that an agreeing pronoun may be more deeply embedded in the clause (here as object of an oblique). Such examples are accounted for by extending the set of possible paths upwards to include OBL OBJ: ${ }^{12}$

(46) d-ez

$$
\text { zir } \quad \mathrm{d}-\mathrm{e}<\mathrm{r}>\mathrm{q}^{\mathrm{S}} \mathrm{a}-\mathrm{r}-\mathrm{s} \mathrm{i}
$$

II.SG-1SG.DAT behind II.SG- < IPFV $>$ go-IPFV-CVB II.SG-be.PRS

She goes after me (male speaking).

(47) $b-e z$

$$
\begin{aligned}
& (\uparrow \text { PRED })=\text { 'PRO' } \\
& (\uparrow \text { NUM })=\mathrm{SG} \\
& (\uparrow \text { PERS })=1 \\
& (\uparrow \text { CASE })=\text { DAT } \\
& \text { @ III.SG((PATHOUT } \uparrow) \text { PIV) }
\end{aligned}
$$

(48) PathOut $\equiv\{$ SUBJ, OBJ, OBL, OBL OBJ $\}$

The same lexically driven approach extends straightforwardly to other unexpectedly agreeing targets. The agreeing postposition exemplified in (49), which subcategorises for its own OBJ function but agrees externally with the clausal absolutive involves the lexical agreement constraint @ IV.SG((OBL $\uparrow)$ PIV)

(49) zari q'onq' okłni ja-b

1SG.ERG book(IV)[SG.ABS] [SG.SG]read.PFV this-III.SG

maq'al-li-ra-k eq'en

chapter(III)-SG.OBL-CONT-LAT [IV.SG] up.to

I read the book up to this chapter.

\footnotetext{
${ }^{12}$ It appears that with a small number of matrix verbs including $k$ łan 'like, love, want' and sini 'know', which take dative subjects, agreement may under some circumstances be controlled by the PIV of the embedded clausal complement. Much fuller investigation of this phenomenon is required, and the path definition given in (48) could in principle be expanded for such cases. We leave this matter for future research.
} 
Similarly for examples of agreeing adverbs - the adverb in (50) is lexically associated with the agreement constraint @ III.SG $(($ ADJ $\in \uparrow)$ PIV $) .{ }^{13}$

$$
\begin{aligned}
& \text { (50) godo-b mahla } \quad \text { gudu-m-mi horo:keij }<\mathrm{b}>\mathrm{u} \\
& \text { that-III.SG house(III)[SG.ABS] that-1.SG-SG.ERG long.time.ago }<\text { III.SG }> \\
& \begin{array}{ll}
\mathrm{a}<\mathrm{b}>\mathrm{u}-\mathrm{li} & \mathrm{e}<\mathrm{b}>\text { di } \\
<\text { III.SG }>\text { make.PFV-CVB } & \text { [III.SG]be.PST }
\end{array}
\end{aligned}
$$

He built that house a very long time ago.

A final interesting case is that of the emphatic element presented in Chapter 2. Of course there is no need for an element to be a separate constituent to be associated with an agreement constraint, and the emphatic particle attaches to a range of different elements, introducing some emphatic meaning and inducing agreement with the clausal absolutive. Given its promiscuous attachment possibilities, the range of possibilities for PATHOUT in the case of the emphatic is also correspondingly wide. Our hypothesis is that a single inside-out functional uncertainty (PATHOUT) can be defined in the grammar and used in the statement of agreement constraints across all these additional agreement targets.

To close this section, we have seen that the set of possible agreement targets for clausal agreement, represented schematically in (51), are captured by formulating simple outside-in and inside-out agreement contraints associated with the agreement targets. As a visual aid, we can represent schematically the range of targets we have discussed in (51), in which the controller is the PIVOT.

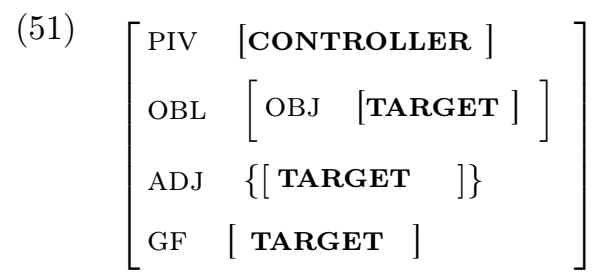

\section{Agreement in the Nominal Domain}

In this section we discuss head modifier agreement within the Archi nominal domain. As outlined in Bond and Chumakina (to appear), agreement features are not realized on all elements within the nominal domain. Amongst what we might think of broadly as determining elements, quantifiers show no agreement, while demonstratives and numerals show agreement in NUM and GEND. Among possessor arguments, genitive nouns show no agreement while a subject of genitive pronouns show agreement in NUM and GEN. A similar split behaviour is

\footnotetext{
${ }^{13}$ Recall that ADJ is a set-valued feature: $\in$ may be used in the path in the f-descriptions $(\downarrow \in(\uparrow \mathrm{ADJ}) \equiv(\uparrow \mathrm{ADJ} \in)=\downarrow)$. The formalism supports both Outside-In $(\uparrow \mathrm{GF})$ and Inside-Out (GF $\uparrow)$ expressions.
} 
found with attributive modifiers, where nominal-adjectives (26 members, covering ethnicity, properties and quantities) show no agreement and attributives agree in NUM and GEND.

There are two approaches possible for agreement within the NP, which we can call the co-specification approach and the matching approach. In the former approach, agreement targets simply co-describe (define or constrain features of) the f-structure of the NP as a whole. In the latter approach, the f-structure of the target and that of the controller match in agreement features (clearly the question of a matching approach does not arise when controller and target are coheads of one and the same f-structure). Here we will adopt the co-specificational approach throughout, a choice which reflects the fact that the features are intrinsic or inherent to the controller, although they may be expressed on one or both of the controller and target(s). Other agreement phenomena, of course, may motivate the use of a feature matching approach elsewhere.

\subsection{Possessors}

Recall that first person (genitive) possessors agree with the head noun in NUM and GEND, although other possessors (including the rest of the genitive pronominal paradigm) do not exhibit agreement. An example is given in (52); the f-structure for (52a) is shown in (53).

$$
\begin{aligned}
& \text { a. w-is ušdu } \\
& \text { I.SG-1SG.GEN brother(I)[ABS.SG] } \\
& \text { my brother } \\
& \text { b. d-is došdur } \\
& \text { II.SG-1SG.GEN sister(II) [ABS.SG] } \\
& \text { my sister }
\end{aligned}
$$

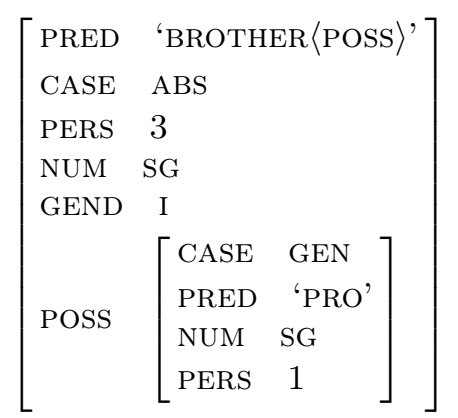

The lexical description of $w$-is will introduce the agreement constraints shown in (54). Given the template definitions in (23), the lexical entry is as in (55) (obviously, the templates can also be used to express the pronouns' own intrinsic agreement features, with the appropriate parameter value). 
(54) $(($ POSS $\uparrow) ~ N U M)=S G$

$((\operatorname{POSS} \uparrow)$ GEND $)=\mathrm{I}$

(55) w-is

$$
\begin{aligned}
& (\uparrow \text { PRED })=\text { 'PRO' } \\
& (\uparrow \mathrm{NUM})=\mathrm{SG} \\
& (\uparrow \mathrm{PERS})=1 \\
& (\uparrow \mathrm{CASE})=\mathrm{GEN} \\
& \text { @I.SG (POSS } \uparrow)
\end{aligned}
$$

Note that we do not have to specify any sort of null or default agreement for non-agreeing pronominals: the morphology should produce all and only the correctly inflected forms.

\subsection{Attributives}

Bond and Chumakina (to appear) note that attributives can be derived from most parts of speech, by use of the attributive suffix -t:u. In the case of an attributive from an inflected verb being used as a nominal modifier, we will see agreement on the verbal base (with the absolutive PIV), as well as agreement with the nominal it modifies.

We start with a simple example of an attributive from a stative verb, as in (56).

(56) mu-t:u

$$
\text { bošor }
$$

be.beautiful-ATTR.I.SG man(I)[SG.ABS]

handsome man

On the simplest assumptions about the f-structure of an attributive modifier from a stative verb, we would posit the f-structure in (57). The head noun and the attributive modifier will both contribute NUM and GEND values for the f-structure of the NP as a whole. Hence if these clash, then the result will be ungrammatical.

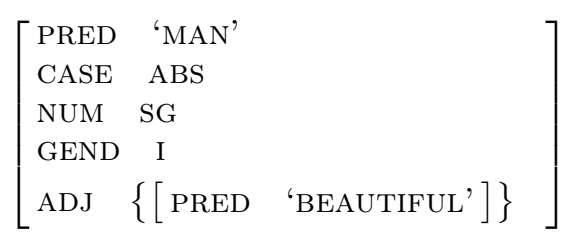

The lexical information associated with the modifying use of the attributive is as in (58): the attributive specifies information about the containing f-structure 
(that of the NP as a whole) by means of inside out statements. ${ }^{14}$

(58) $m u-t: u \quad(\uparrow$ PRED $)=$ 'BEAUTIFUL'

@I.SG $(\mathrm{ADJ} \in \uparrow)$

An attributive can function as the predicative complement of a copula in which case it shows agreement with the noun that it is predicated of, which is the clausal subject. We will return to these cases below.

\subsection{Coordination of Attributive Modifiers}

Attributives can be coordinated, so our account of agreement will need to take account of this. An example is given in (59).

(59) jamu-r mu-t:u-r-u hiba-t:u-r-u

that-II.SG be.good-ATTR-II.SG-COORD be.beautiful-ATTR-II.SG-COORD

lo d-i-kul-l-a

lass(II)[SG.ABS] II.SG-be.PRS-NMLZR-OBL-IN

Since she was a beautiful and good girl... Bond and Chumakina (to appear)

It is well beyond the scope of the current chapter to develop an analysis of coordination in Archi, but we can outline the general form of an LFG approach to the interaction of attributive agreement with coordination. Coordinate structures are treated as sets in LFG. For concreteness in what follows, we will treat the attributes as adjectives in terms of c-structure category (see Bond and Chumakina (to appear) for discussion of their syntactic categorial status, inter alia). A coordinate attribute phrase might be introduced by a rule along the lines of (60). Each daughter AP corresponds to a member of a set of f-structures, giving a structure as shown schematically in (61), where $c$ is the f-structure of the mother AP node and $g$ and $b$ the f-structures of the daughter AP nodes.

(60) $\mathrm{AP} \longrightarrow$

$\mathrm{AP}$

$\downarrow \in \uparrow$

$(\downarrow$ CONJFORM)

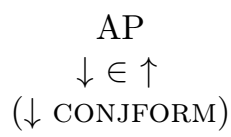

\footnotetext{
${ }^{14}$ The alternative approach using matching would specify that the adjunct matches the $\mathrm{N}$ in agreement features. Given that attributives and nominal adjectives can freely reorder (subject to some semantic restrictions) we might think they are members of the same cstructure category. A matching approach would then specify agreement features for adjectives which never show agreement, which is rather unfortunate. This might constitute grounds for preferring the co-specificational approach.
} 
$(61)$

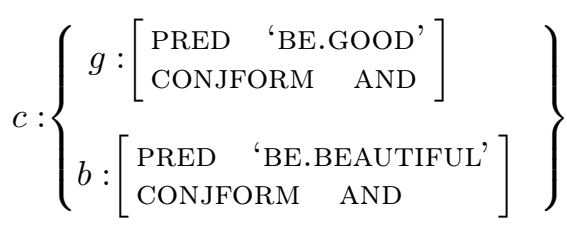

The adjunct AP modifying the nominal is itself annotated $\downarrow \in(\uparrow$ ADJ) as shown in $(62)$... again the precise c-structure category itself is not important here. The f-structure of the coordinate structure as a whole $(c)$ is a member of the adjunct set $(a)$, so the structure of the NP is as shown in (63).

(62) $\mathrm{NP} \longrightarrow$

$$
\begin{array}{ll}
\mathrm{AP}^{*} & \mathrm{~N} \\
\downarrow \in(\uparrow \mathrm{ADJ}) & \uparrow=\downarrow
\end{array}
$$

$$
\left[\begin{array}{l}
\text { PRED } \\
\text { NUM } \\
\text { GEND }
\end{array}\right.
$$

This shows us that a simple extension to the inside-out statement of the sort shown in (58) is required to allow for the possibility of coordination of $\mathrm{N}$ modifying attributives. The path which is the value of the agreement agreement templates (defined in (23) above) is defined in (64): recall that Kleene plus denotes one or more $\in$ attributes: clearly, there is always one /in on the path, as ADJUNCT is a set-valued attribute.

(64) Attributive Modifier Agreement Path: $\left(\mathrm{ADJ} \in^{+} \uparrow\right)$

\subsection{Attributive Modifers from Other Bases}

Attributives are not only formed from stative verbal bases, but may also be based on other parts of speech including postpositions and nouns. (65) is an example of the former.

(65) iškol-li-s xir-t:u-t nokd' school(IV)-SG.OBL-DAT behind-ATTR-IV.sG house(IV).[SG.ABS] ak:u-ra? [IV.SG]see.PFV-QUEST

Do you see the house behind the school? 
Here the postpositional phrase headed by the postposition $\chi$ ir 'behind' modifies noky' 'house' and agrees with it in NUM and GEND (IV.SG) (nokt is also the clause agreement controller, of course). The head of the modifying phrase also governs a dative marked argument (which I have represented in (66) as the OBJ of the postposition).

$$
\left[\begin{array}{lll}
\text { PRED } & \text { 'HOUSE' } & \\
\text { CASE } & \text { ABS } & \\
\text { NUM } & \text { SG } & \\
\text { GEND } & \text { IV } & \\
\text { ADJ } & \left\{\left[\begin{array}{ll}
\text { PRED } & \text { 'BEHIND }<\text { OBJ>' } \\
\text { OBJ } & {\left[\begin{array}{ll}
\text { PRED } & \text { 'SCHOOL' } \\
\text { CASE } & \text { DAT } \\
\text { NUM } & \text { SG } \\
\text { GEND } & \text { IV }
\end{array}\right]}
\end{array}\right]\right)
\end{array}\right]
$$

No modification is needed to the proposals made so far to cover these cases: the postposition can be associated with agreement information as shown in (67). We have formulated the agreement to allow for interaction with coordination, should the ADJ set itself contain a coordinate structure, pending more data.

$$
\begin{aligned}
& \chi i r-t: u-t \quad(\uparrow \text { PRED })=\text { 'BEHIND }<\mathrm{OBJ}>\text { ' } \\
& (\uparrow \text { OBJ CASE })={ }_{c} \text { DAT } \\
& \text { @IV.SG (ADJ } \left.\in^{+} \uparrow\right)
\end{aligned}
$$

Attributives can also be transposed from nouns. The example in (68) involves a dative case form of the nominal, expressing a beneficiary argument, and hence attributive adjuncts from nominal bases will be associated with agreement constraints in similar fashion to attributives transposed from stative verbs or a postposition.

(68)

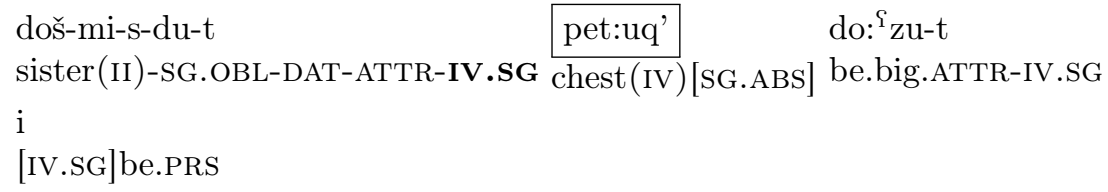

doš-mi-s-du-t pet:uq' do: ${ }^{\mathrm{S}} \mathrm{zu}-\mathrm{t}$ sister(II)-SG.OBL-DAT-ATTR-IV.SG chest(IV)[SG.ABS] be.big.ATTR-IV.SG i [IV.SG]be.PRS

The dowry chest for sister is big. Bond and Chumakina (to appear)

\subsection{More on Deverbals}

We saw in (56) above the treatment of a simple attributive from a stative verbal base. However deverbal attributives from dynamic verbs may also show 'internal' agreement with an absolutive argument of the verbal base. For example in 
(69) the attributive shows (prefixal) agreement in NG with the absolutive argument of 'milk' and also agrees with the nominal it modifies (the final $t$ :ur for II.SG). In (70) the attributive modifier shows IV.SG agreement with the nominal saianna 'hour' and I.SG agreement with the (male) absolutive argument of the verbal base ( $t u-w$ 'that one').

(69) $\chi^{\text {f }}$ on

b-a $<$ r $>$ ca-t:ur lo cow(III)[SG.ABS] III.SG-<IPFV $>$ milk-IPFV-ATTR-II.SG girl(II)[SG.ABS] the girl who is milking the cow

(70) tu-w $\mathrm{q}^{\mathrm{w} \text { i }} \mathrm{a}-\mathrm{t}: \mathrm{u}-\mathrm{t}$ saianna that.I.SG[ABS] I.SG.come.PFV-ATTR-IV.sG hour(IV).IN tu-w-mi-r-ši ba that-I.SG-SG.OBL-CONT-ALL talk.IMP

when he approaches (lit: at the time after he has come), talk to him Bond and Chumakina (to appear)

Providing a complete analysis of deverbal attributives goes well beyond the scope of this chapter, but some aspects of their properties are clear. Attributivised verbs preserve the ability to project and case mark their arguments, and examples such as (70) show that it is not a requirement that one argument of the verb corresponds to the nominal which the attributive as a whole modifies. The structure of such examples thus appears to be along the lines shown in (71) for $(70)$.

$$
\left[\begin{array}{ll}
\text { PRED } & \text { 'HOUR' } \\
\text { NUM } & \text { SG } \\
\text { GEND } & \text { IV } \\
\text { ADJ } & \left\{\left[\begin{array}{ll}
\text { SUBJ } & {\left[\begin{array}{ll}
\text { PRED } & \text { 'PRO' } \\
\text { CASE } & \text { ABS } \\
\text { NUM } & \text { SG } \\
\text { GEND } & \text { I }
\end{array}\right]} \\
\text { PRED } & \text { 'COME }<\text { SUBJ }>
\end{array}\right]\right\}
\end{array}\right]
$$

From the point of view of agreement, these structures do not pose any particular difficulty, though they are interesting in their own right. The account of attributive modifier agreement summarised in (64) above already covers them. Further evidence that such deverbal attributives (may) project all their arguments is provided by (72) from Bond and Chumakina (to appear), in which the external nominal $q$ waridkul corresponds to the unexpressed internal absolutive argument, and hence appears to control both external and internal agreement, including agreement on the dative argument of the verbal base. It is clear from such examples that the verbal f-structure contains an unexpressed PRO argument. 
(72) ez

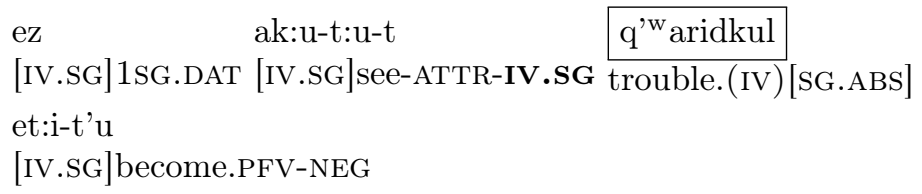

there was no more trouble for me (lit. trouble seen by me) Bond and Chumakina (to appear)

Returning now to the analysis of (69), we see that the case assigned internally (within the verbal f-structure) and externally (within the nominal f-structure) to the modified argument differ, militating against an analysis in terms of structure-sharing. The f-structure proposed for (69) is along the lines shown in $(73) \cdot{ }^{15}$

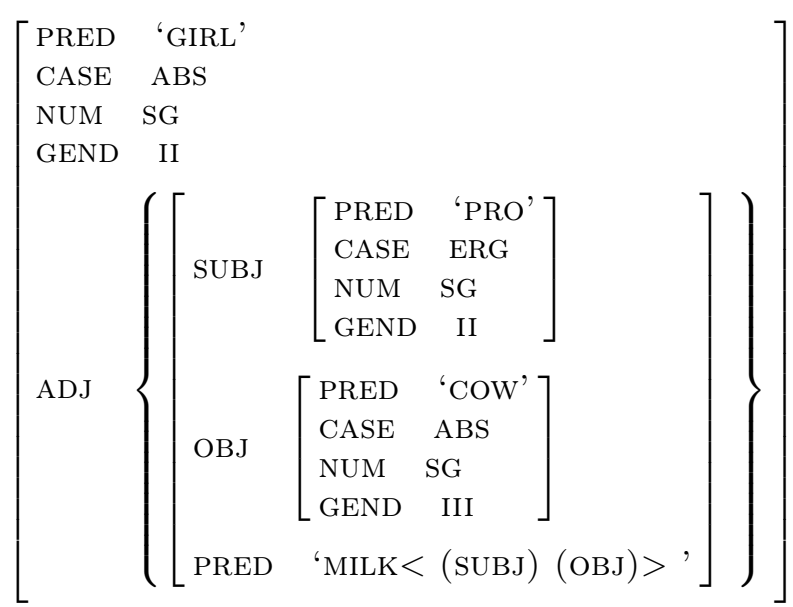

The lexical entry for the deverbal attributive $b$-a $<r>c a-t$ :ur is along the lines shown in (74), which expresses the fact that it shows (internal, predicateargument) agreement with the PIV argument (like a verb) and (external, headmodifier) agreement with the head of the containing f-structure (like other adjuncts to nominal heads).

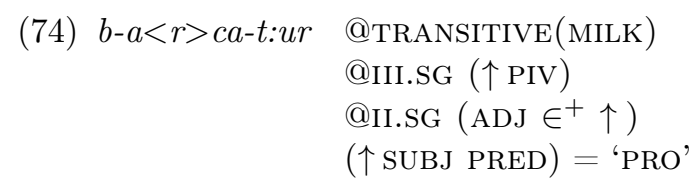

\footnotetext{
${ }^{15}$ In LFG there is no requirement that such unexpressed arguments correspond to null elements in the c-structure. A typical case is the unexpressed subject of participial modifiers, which is generally taken to be introduced lexically.
} 


\subsection{Numerals}

Before leaving the topic of NP-internal head modifier agreement, we will briefly touch on the behaviour of numerals, a topic which provides some evidence that the values of INDEX and CONCORD may diverge in Archi, and hence provides motivation for the postulation of two distinct sets of syntactic agreement features in that language. ${ }^{16}$

Example (75) shows IV.SG agreement throughout, indicating that $4:{ }^{w} e j<t^{\prime}>u$ nokf' 'five houses' is SG both from the point of view of predicate-argument agreement and NP-internal head modifier agreement. This is unproblematic, and consistent with the idea that syntactic agreement (whether it targets INDEX features or CONCORD features), is fundamentally a syntactic phenomenon. ${ }^{17}$

(75) zari $\quad \mathrm{d}$ : $^{\mathrm{w}} \mathrm{ej}<\mathrm{t}^{\prime}>\mathrm{u} \quad$ nokł'

aw

1SG.ERG five $<$ IV.SG $>$ house(IV)[SG.ABS] [IV.SG]make.PFV

I built five houses.

In (76), on the other hand, we see that an NP which has human reference controls plural agreement on the verb while agreement within the NP (between the numeral and the head noun), is singular. With numerally quantified human NPs, then, we might conclude that we have evidence that CONCORD and INDEX may not match. ${ }^{18}$

(76) os $\quad \mathrm{e}<\mathrm{b}>$ di-li

$\mathrm{e}<\mathrm{b}>$ di-t'u

dib-aw kulu

one $<$ I $/$ II.PL $>$ be.PST-EVID $<$ I/II.PL $>$ be.PST-NEG three-I.SG orphan

lo

$\operatorname{lad}(\mathrm{I})[\mathrm{I} . \mathrm{SG}]$

Once upon a time there were three orphan boys.

Consider first (75) and the f-structure (77) for the nominal phrase in this sentence.

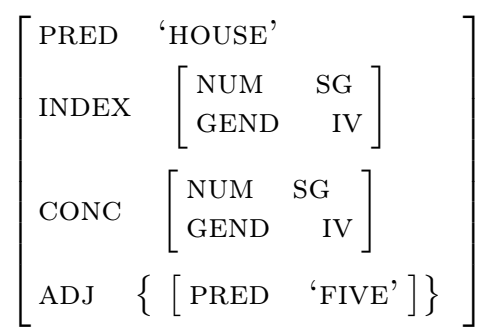

\footnotetext{
${ }^{16}$ Further evidence may come from the behaviour of quantifiers and from coordination.

${ }^{17}$ Of course, it is certainly the case that there is a clear tendency for INDEx features to be closer to semantic features/values than are CONCORD features, and conditioned by semantic factors, but the point is that INDEX features are syntactic features.

${ }^{18}$ Recall that throughout the rest of this chapter we simply ignore the additional structure induced by separating INDEX from CONCORD, as orthogonal to our concerns, and simply refer directly to NUM, GEND and PERS.
} 
The lexical entries are shown in (78) and (79). As we have observed, numerals specify singular CONCORD constraints over the f-structure of the NP. Nominals with non-human reference will have lexical descriptions in which the values of CONCORD and INDEX number match.

$$
\begin{aligned}
4:{ }^{w} e j<t>u & (\uparrow \text { PRED })=\text { 'FIVE' } \\
& ((\text { ADJ } \in \uparrow) \text { CONC NUM })=\mathrm{SG} \\
& ((\text { ADJ } \in \uparrow) \text { CONC GEND })=\mathrm{IV}
\end{aligned}
$$

(79) nokł'

$$
\begin{aligned}
& (\uparrow \text { PRED })=\text { 'HOUSE' } \\
& (\uparrow \text { CONC NUM })=\mathrm{SG} \\
& (\uparrow \mathrm{CONC} \text { GEND })=\mathrm{IV} \\
& (\uparrow \mathrm{IND} \text { NUM })=\mathrm{SG} \\
& (\uparrow \mathrm{IND} \text { GEND })=\mathrm{IV} \\
& (\uparrow \mathrm{CASE})=\mathrm{ABS}
\end{aligned}
$$

Consider now the example (76) in which the verb shows plural agreement while the nominal and the numeral show SG concord: (80) is the f-structure for the NP. (The particular lexical item $l o$ is in fact underspecified or indeterminate with respect to feminine and masculine reference, and hence can bear either gender I or II features, but we are not concerned with that issue here.) Verbal (and other clausal predicate agreement) will target the controller's INDEX features, and NP internal agreement on attributives and numerals apparently targets the controller's CONCORD features.

$$
\left[\begin{array}{ll}
\text { PRED } & \text { 'LAD' } \\
\text { INDEX } & {\left[\begin{array}{lr}
\text { NUM } & \text { PL } \\
\text { GEND } & \text { I }
\end{array}\right]} \\
\text { CONC } & {\left[\begin{array}{lr}
\text { NUM } & \text { SG } \\
\text { GEND } & \text { I }
\end{array}\right]} \\
\text { ADJ } & \{[\text { PRED 'THREE' }]\}
\end{array}\right]
$$

It seems that 'human' nouns do not have their INDEX NUM fixed lexically, but they may have a plural INDEX in the presence of a numeral quantifier. There are several ways in which this can be expressed. ${ }^{19}$ One possibility is along the lines shown in the (verbose) lexical entry for $l o$ in (81), where we additionally assume NQ as a value for a TYPE attribute on adjuncts. The disjunction in (81) allows the f-structure of $l o$ to either have a plural INDEX NUM in the presence of a numeral or to have a singular INDEX NUM.

\footnotetext{
${ }^{19}$ We do not rule out the possibility that the relevant distinction is between general number and plural, rather than singular and plural, in fact.
} 
(81) lo

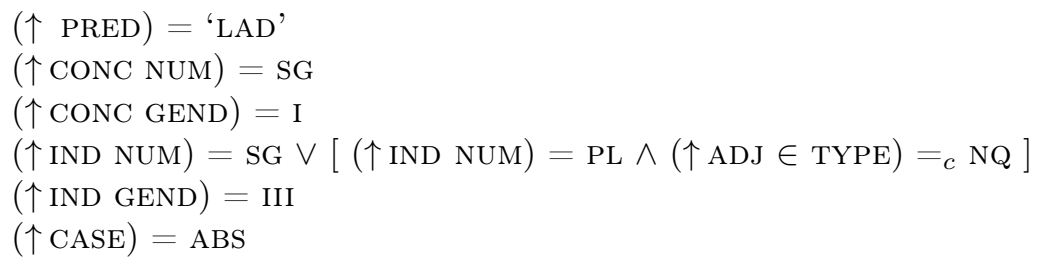

Notice that as specified this entry allows a numerally quantified 'human' noun to be associated with a singular INDEx, and this is what we see in examples such as the following:

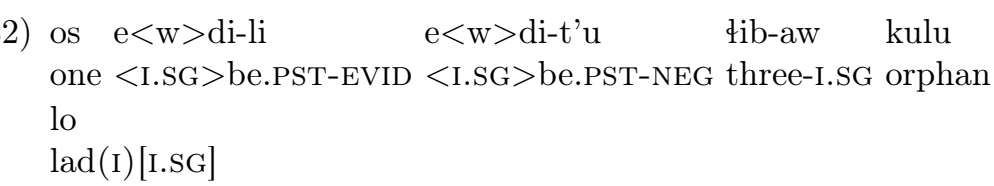

Once upon a time there were three orphan boys.

\section{Biabsolutives}

In this section we return to the issue of clausal agreement and consider possible approaches to biabsolutive clauses in Archi. Biabsolutives occur as an alternative to ergative-absolutive and dative-absolutive alignments. They are found only in periphrastic constructions involving a copula and a converb, and their distribution is conditioned by the form of the converb. Since the evidence is that both absolutives are full syntactic arguments, such clauses potentially contain two ABS agreement controllers. The observed pattern in the biabsolutive construction (BAC) is that the converb agrees with the OBJ absolutive irrespective of whether the SUBJ is also absolutive, while the copula agrees with the highest (most prominent) absolutive-marked argument (that is, with the SUBJ if it is absolutive). A minimal pair showing contrasting ergative and biabsolutive alignment is shown in (83)-(84).

(83) But:a-mu buq' b-e $<$ r $>$ k'u-r-ši Butta(I)-SG.ERG grain(III)[SG.ABS] III.SG- $<$ IPFV $>$ sort-IPFV-CVB b-i III.SG-be.PRS

Butta is sorting grain.

(84)

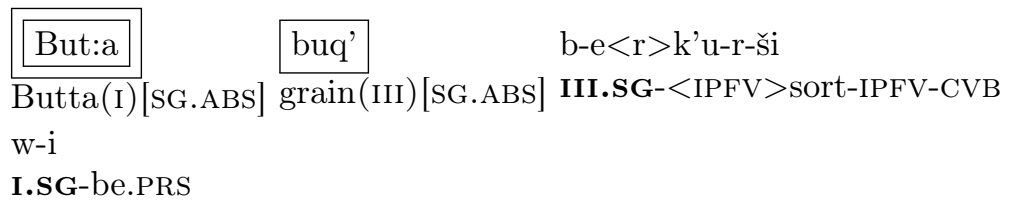

Butta is sorting grain. 
The biabsolutive construction is limited to clauses involving verbal periphrasis, combining a converb with a copula, but it is not permitted in all such periphrastic constructions. ${ }^{20}$ It seems that the BAC occurs as an alternative to the ergative-absolutive or dative-absolutive alignment only when the converb is built on the imperfective stem. It is optional for imperfective converbs in $-\check{s}$ (corresponding to ASP = IPFV.SIMUL in our f-structures), illustrated in (83)-(84) above, and is obligatory when the imperfective converb stem is suffixed with mat, shown in (85) (corresponding to ASP = IPFV.CONT in our f-structures). The distribution of the $\mathrm{BAC}$ is independent of the choice of present or past tense copula in the verbal periphrasis.

(85)

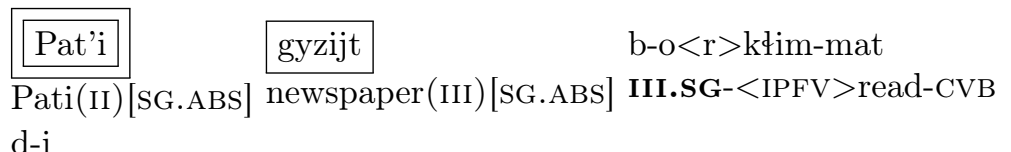

d-i

II.SG-be.PRS

Pati is still reading the newspaper.

To give an account of the BAC it is necessary to provide a concrete analysis of converb + copula verbal syntactic periphrases in Archi. From an LFG perspective, there are two main contenders, the so-called Aux-Pred analysis and the Aux-Feature analysis. In the former approach, the copula (or other auxiliary verb) projects its own PRED value and subcategorises for an open complement (XCOMP), comparable to a subject raising verb. In the second approach, the copula (or other auxiliary verb) is treated as a purely functional element and shares the f-structure of the main verb, as a co-head. These approaches may be appropriate for different auxiliary verb constructions in one and the same language, a position which is in fact argued for by Falk (2008) for English. Falk proposes that the aspectual auxiliary have in English is purely functional, giving a representation along the lines of (86) for Kim has yawned.

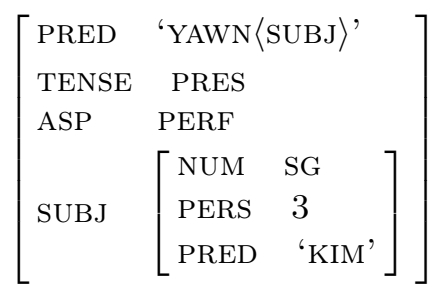

On the other hand, he proposes that progressive be is a raising predicate and hence has a PRED value. The f-structure for Kim is yawning on his analysis is shown in (87).

\footnotetext{
${ }^{20}$ See Chumakina (2012) for extensive defence of the position that Archi converb+copula constructions are properly viewed as morphological and syntactic periphrastic tenses.
} 


$$
\left[\begin{array}{ll}
\text { PRED } & \text { 'BE }<\text { XCOMP }>\text { SUBJ' } \\
\text { TENSE } & \text { PRES } \\
\text { SUBJ } & {\left[\begin{array}{ll}
\text { PRED } & \text { 'KIM' } \\
\text { NUM } & \text { SG } \\
\text { PERS } & 3
\end{array}\right]} \\
\text { XCOMP } & {\left[\begin{array}{ll}
\text { ASP } & \text { PROG } \\
\text { PRED } & \text { 'YAWN }<\text { SUBJ } \\
\text { SUBJ }
\end{array}\right]}
\end{array}\right]
$$

One might consider it possible that imperfective converb constructions and perfective (and potential) converb constructions differ in terms of whether they correspond to a single f-structure or a two-tier f-structure. But notice first that, while such an analysis is technically possible, it entails that the single copula in Archi is ambiguous between an Aux-Pred and an Aux-Feature analysis in its verbal periphrastic use, which does not seem very likely. More importantly, positing such a single/dual tier f-structure is at least partly orthogonal to the issue of the distribution and analysis of the biabsolutive construction, because although the BAC is limited to converbs on imperfective stems, it is not required for these converbs (it is optional for converbs in $\check{s} i$ on imperfective stems. Finally, if clausal agreement were formulated simply in terms of agreement with the clausal absolutive, positing a two-tier f-structure would not in fact remove the challenge posed by the existence of two absolutive arguments in the same clause (or f-structure) to such a (hypothetical) approach. ${ }^{21}$ This is because the Aux-Pred (raising) analysis of verbal complexes, the non-thematic suBJ of the auxiliary is structure-shared with the XCOMP SUBJ, as shown in (87), and hence both (absolutive) arguments are in fact in the same f-structure.

In what follows, we will assume that ergative-absolutive, dative-absolutive and biabsolutive clauses are all 'single-tier' that is, correspond to a single f-structure. On this view, all the cases of verbal periphrasis involve the same basic representation, and we posit a single analysis (an Aux-feat) analysis, for the copula in periphrastic constructions. Some evidence in favour of the monoclausal view (of biabsolutives) may come from negation. In perfective and imperfective biabsolutive clauses such as (88), as in other periphrastic clauses, clausal negation is marked on the auxiliary and not on the converb, although converbs may be directly negated in other constructions. ${ }^{22}$ It is not possible to negate both the auxiliary and the converb.

\footnotetext{
${ }^{21}$ Of course the approach explored here is not formulated in these terms terms but also make reference to the function (as PIV) of the absolutive marked argument.

${ }^{22}$ However negation also occurs on the converb from a potential stem in a BAC, with a habitual meaning.
} 
(88) Pat'i k'ob o $<$ r $>$ c'u-r-ši

Pati(II)[SG.ABS] clothes(IV)[SG.ABS] [IV.SG] <IPFV > wash-IPFV-CVB

d-i-t'u

II.SG-be.PRS-NEG

Pati is not washing the clothes.

Further, there is considerable evidence that the 'biabsolutive problem' in general cannot be solved by claiming that all such constructions are biclausal, and that the two absolutives are in two different agreement domains. A particularly nice illustration of this is provided by Avar. In the ergative construction shown in (89), both the agreement slots in the participle are controlled by the absolutive argument. In the biabsolutive construction in (90), the participle itself agrees with both absolutive arguments, suggesting that they are indeed both in the same clausal structure (or f-structure).
(89) qart.ā
Saka
b-eč'-ule-b
b-ugo

sorceress(II):ERG cow(III):ABS III-milk-PAPRS-III III-be.PRS

The sorceress is milking the cow.

Avar, van den Berg (2005, 179)

(90) qartay

Saka

b-eč'-ule-y

$\mathrm{y}$-igo

sorceress(II):ABS cow(III):ABS III-milk-PAPRS-II II-be.PRS

The sorceress is (engaged in) milking the cow.

Avar, van den Berg (2005, 179)

In a study of the biabsolutive in two other Nakh-Daghestanian languages, Gagliardi et al. (2014) argue in detail for a biclausal analysis of Tsez but a monoclausal analysis of Lak, providing further evidence for the monoclausal analysis of at least some biabsolutive constructions.

The analysis I will explore here will posit virtually identical syntactic structures for the ergative and the biabsolutive constructions. The structures for (83) and (84) differ only in the CASE of the SUBJ, shown in boldface in (91). ${ }^{23}$

\footnotetext{
${ }^{23}$ This in no way commits us to a position in which the semantics of clauses with biabsolutive and ergative alignment are identical. A simple introduction to meaning composition in LFG can be found in Dalrymple (2001).
} 
$(91)$

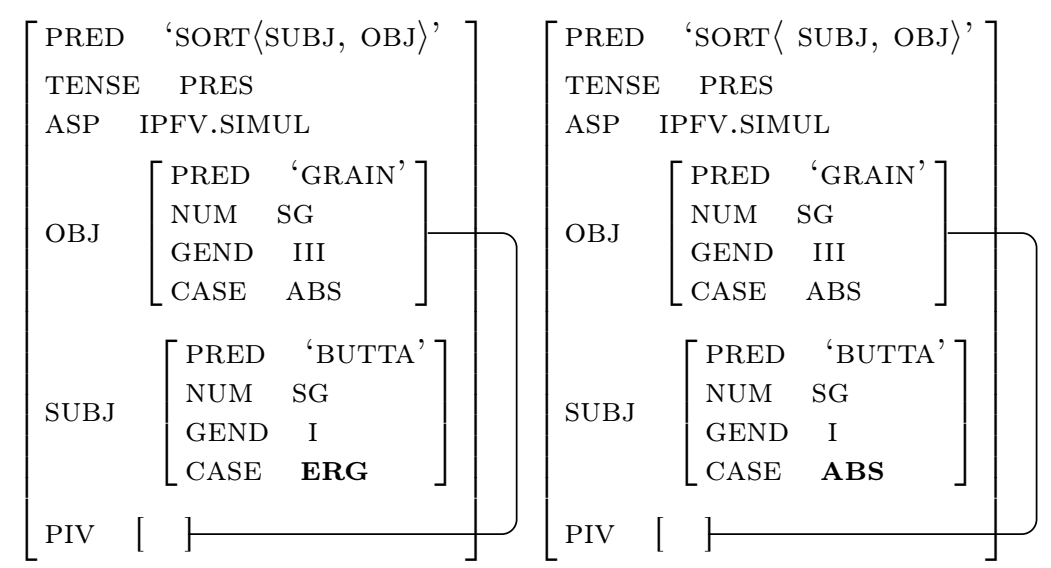

Consider first the lexical descriptions of the converbs, as used in periphrastic (tense and aspect) constructions. A converb on a perfective stem does not permit the biabsolutive alignment. We illustrate the lexical description for this class of converbs with the transitive predicate 'tie', and a IV.SG object (PIV). The (partial) lexical description of the converb is very similar to that of the finite verb, and calls the same templates. The succinct statement in (92) corresponds to the more verbose (93).

$$
\begin{aligned}
\text { et'ni-li } & \text { @TRANSITIVE(TIE) } \\
& \text { @IV.SG( } \uparrow \text { PIV) } \\
& (\uparrow \mathrm{ASP})=\text { PFV.CONSEC }
\end{aligned}
$$

$$
\begin{aligned}
\text { et'ni-li } & (\uparrow \text { PRED })={ }^{\prime T I E}<\text { SUBJ, OBJ }>> \\
& (\uparrow \text { ASP })=\text { PFV.CONSEC } \\
& (\uparrow \text { SUBJ CASE })=\text { ERG } \\
& (\uparrow \text { OBJ CASE })=\text { ABS } \\
& \text { @IV.SG }(\uparrow \text { PIV })
\end{aligned}
$$

Imperfective converbs in -mat are obligatorily biabsolutive rather than ergativeabsolutive (or dative-absolutive). The verbose lexical description for the periphrastic use of such converbs is as shown in (94). ${ }^{24}$

$$
\begin{aligned}
\text { (94) e<r>t'im-mat } & (\uparrow \mathrm{PRED})=\text { 'TIE }<\mathrm{SUBJ}, \mathrm{OBJ}> \\
& (\uparrow \mathrm{ASP})=\mathrm{IPFV} . \mathrm{CONT} \\
& (\uparrow \mathrm{OBJ} \mathrm{CASE})=\mathrm{ABS} \\
& (\uparrow \mathrm{SUBJ} \mathrm{CASE})=\mathrm{ABS} \\
& @ \mathrm{IV} . \mathrm{SG}(\uparrow \mathrm{PIV})
\end{aligned}
$$

\footnotetext{
${ }^{24}$ For simplicity of presentation we exclude reference to other uses of the converbs from the abbreviated lexical descriptions given here.
} 
We may define a further template for the biabsolutives as in (95) and re-express (94) more succinctly. The BAC template introduces a two argument relation for the PRED value (recall that the parameter value is given by the lexical entry) and specifies a biabsolutive case alignment. It is very likely that further semantic and/or information structure related properties and information are associated with the biabsolutive mapping. The BAC template may be an appropriate locus for the statement of such information, but we restrict attention here to purely syntactic matters. The more succinct lexical description for the imperfective converb in -mat is shown in (96).

$$
\begin{aligned}
(95) \mathbf{B A C}(\mathbf{F N}) \equiv \quad & (\uparrow \mathrm{PRED})={ }^{\circ} \mathrm{FN}<\mathrm{SUBJ}, \mathrm{OBJ}> \\
& (\uparrow \mathrm{SUBJ} \mathrm{CASE})=\mathrm{ABS} \\
& (\uparrow \mathrm{OBJ} \mathrm{CASE})=\mathrm{ABS} \\
(96) e<r>t^{\prime} i m-m a t \quad & @ \mathrm{BAC}(\mathrm{TIE}) \\
& \text { @IV.SG }(\uparrow \mathrm{PIV}) \\
& (\uparrow \mathrm{ASP})=\mathrm{IPFV} . \mathrm{CONT}
\end{aligned}
$$

Finally, optional biabsolutive converbs will allow either the TRANSITIVE or the BAC template, as shown for the IPFV.SIMUL converb for 'tie' in (97).

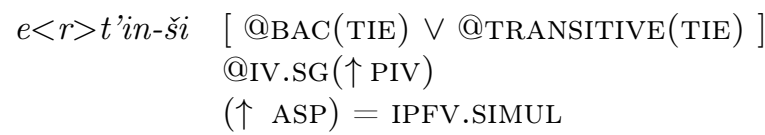

We must now specify the copula. Unlike other finite verbs, which agree with the PIV, we see that the copula in periphrastic converb constructions agrees with the highest absolutive argument. ${ }^{25}$ This is captured in the lexical description in (98). The second line contains an existential constraint, requiring the f-structure that the (temporal, periphrastic) copula occurs in to contain some value for the feature ASP: this does not itself define a value for this feature, so permits the copula to co-occur with the range of possible converbs. The agreement properties of the copula are stated in the disjunction: either the copula agrees with the PIV and the SUBJ is not ABS, or it agrees with the absolutive SUBJ.

$$
\begin{aligned}
\text { (98) w-i } & (\uparrow \text { TENSE })=\text { PRES } \\
& (\uparrow \mathrm{ASP}) \\
& {[[\text { @I.SG }(\uparrow \mathrm{PIV}) \wedge(\uparrow \mathrm{SUBJ} \text { CASE }) \neq \mathrm{ABS}] \vee} \\
& {[@ \mathrm{I} . \mathrm{SG}(\uparrow \mathrm{SUBJ}) \wedge(\uparrow \mathrm{SUBJ} \mathrm{CASE})=\mathrm{ABS}]] }
\end{aligned}
$$

\footnotetext{
${ }^{25}$ The notion of highest makes implicit reference to a hierarchy of GFs which may be relevant to the statement of constraints. In terms of the feature decomposition of Lexical Mapping Theory (see (Dalrymple, 2001) or Bresnan (2001)) the highest GF, the suBJ, is the least marked $([-\mathrm{O},-\mathrm{r}])$.
} 
Before turning to the matter of other agreement targets in biabsolutive clauses, it is perhaps useful to walk through the analysis of a simple example such as (84) repeated here as (99).

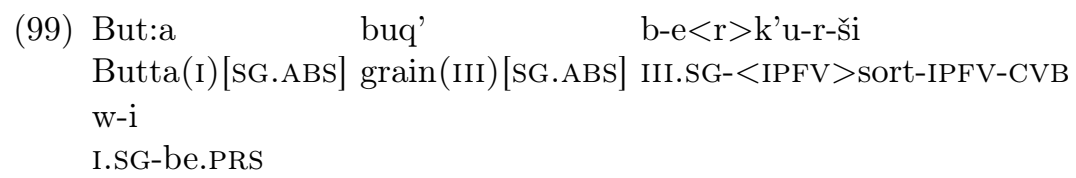

Butta is sorting grain.

The lexical description of the IPFV.CONT converb will be along the lines shown in (97). Together with (98) and appropriate entries for the nouns, the minimal f-structure will be as shown in (100). Since the noun 'Butta' is absolutive, the disjunction in the converb's entry will resolve in favour of @BAC(SORT). The converb agrees with the PIV. Since the SUBJ is absolutive, the copula is required to agree with the SUBJ rather than the PIV.

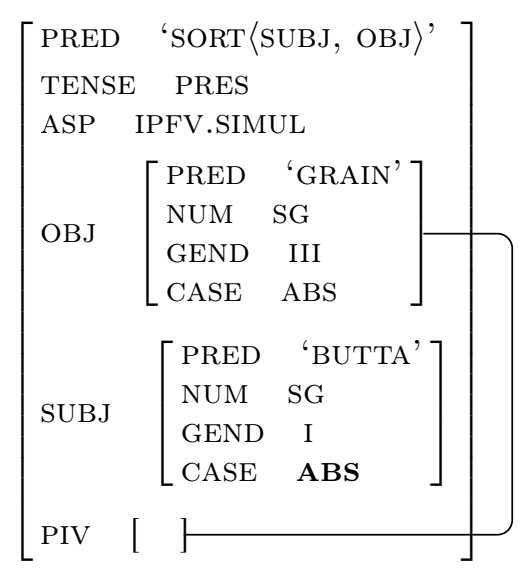

\subsection{Other Agreement Targets}

In general, it appears that other agreement targets continue to agree with the OBJ ABS, that is, the PIV in the biabsolutive construction. This is the behaviour captured by the account of such targets which we have developed here, as they are associated with agreement constraints over the PIV. Note that this agreement pattern is maintained independent of their linear or c-structure position: in (101) and (102) the adverb agrees with the PIV absolutive, whether it occurs before or after the copula (which agrees with the non-pivot absolutive). A similar pattern is seen for an agreeing dative pronoun in (103)-(104). ${ }^{26}$

\footnotetext{
${ }^{26}$ If there is variability, either for some speakers or for particular classes of such agreement targets, we would allow agreement on these elements to be disjunctively specified (with the PIV or with an absolutive SUBJ).
} 
(101) tu-w q'onq' o $<\mathrm{r}>$ kłin-ši $\quad$ w-i that-I.SG.ABS book(IV)[SG.ABS] [IV.SG]read <IPFV>-CVB I.SG-be.PRS dit: $a<t^{\prime}>\mathrm{u}$ early $<$ IV.SG $>$

He is reading a book early.

(102) $\begin{array}{llll}\text { tu-w } & \text { q'onq' } & \text { o }<\text { r }>\text { kłin-ši } & \text { dit:a }<\text { t' }>\text { u } \\ \text { that-I.SG.ABS book(IV)[SG.ABS] } & {[\text { IV.SG]read }<\text { IPFV }>\text {-CVB early }<\text { IV.SG }>}\end{array}$ I.SG-be.PRS

He is reading a book early.

(103) tu-w q'onq' $\quad \mathrm{o}<\mathrm{r}>\mathrm{k}$ łin-ši $\quad$ w-i that-I.SG.ABS book(IV)[SG.ABS] [IV.SG]read $<$ IPFV $>$-CVB I.SG-be.PRS ez [IV.SG]1SG.DAT

He is reading a book for me.

(104)
tu-w q'onq'
$\mathrm{o}<\mathrm{r}>\mathrm{k}$ łin-ši
that-I.SG.ABS book(IV)[SG.ABS] [IV.SG]read $<$ IPFV $>$-CVB
ez
$\mathrm{w}-\mathrm{i}$
[IV.SG]1SG.DAT I.SG-be.PRS

He is reading a book for me.

\section{Conclusion and Summary}

This chapter has discussed how a range of agreement phenomena in Archi may be captured using LFG as a syntactic framework. As noted in the introduction, the strategy adopted here has been to provide analyses which are as firmly routed in the 'LFG perspective' as possible: in a number of cases, alternative approaches, for example using feature matching (sharing) rather than co-specification, could easily be developed within the same framework of syntactic assumptions.

At the clausal level the absolutive argument controls agreement. The evidence suggests that Archi (in common with other Nakh-Daghestanian languages) is morphologically (rather than syntactically) ergative in general. That is, although agreement targets the absolutive $(\mathrm{S} / \mathrm{P})$ argument, other processes may be sensitive to grammatical function. Agreement generalisations may be stated directly over the grammatical functions SUBJ and OBJ, but here we have sketched an approach (following Belyaev (2013) for Dargwa) in which agreement constraints at the clausal level make reference to PIVOT.

Our account of agreement in Archi expresses agreement generalisations by making extensive use of parametrised templates called by lexical entries. This lexical 
treatment allows agreement across the lexicon to be specified in a succinct manner while also allowing for lexical idiosyncracy. The agreement behaviour at both clausal and NP level reduces to a number of simple agreement generalisations. Additional (unusual) targets for agreement controlled by the absolutive argument in the clause express agreement with the controller by means of insideout statements in their lexical entries; and no 'feature passing' in the syntactic tree, or otherwise undermotivated c-structure assumptions are required. We hypothesize that such inside-out statements are constrained (by off-path constraints) to refer upward only to targets within the same clausal domain.

We also presented an LFG approach to the Archi biabsolutive construction in which a (transitive) periphrastic verbal complex combining a form of the copula with an imperfective lexical converb occurs with two absolutive case-marked arguments. Evidence suggests that the Archi BAC is monoclausal, and agreement targets involving different controllers (in the same clause) may display interleaved ordering. Our approach makes reference to the ordering in argument structure of the controllers: in such periphrastic constructions, the copula agrees with the highest absolutive argument (the SUBJ), while the converb agrees with the lowest absolutive (the PIVOT): in most clause types these agreement constraints will simply hold over the same controller - in the BAC they hold over two different controllers.

\section{References}

Arka, I Wayan and Christopher D. Manning. 1998. On the three subjects in Indonesian: Evidence from binding. In M. Butt and T. H. King, eds., Proceedings of the LFG98 Conference, pages 1-21. Stanford, CA: CSLI Publications.

Asudeh, Ash. 2012. The logic of pronominal resumption. Oxford: Oxford University Press.

Asudeh, Ash, Mary Dalrymple, and Ida Toivonen. 2008. Constructions with lexical integrity: Templates as the lexicon-syntax interface. In M. Butt and T. H. King, eds., Proceedings of the LFG08 Conference. Stanford, CA: CSLI Publications: http://www-csli.stanford.edu/publications.

Belyaev, Oleg. 2013. Optimal agreement at m-structure: Person in Dargwa. In M. Butt and T. H. King, eds., Proceedings of the LFG13 Conference. CSLI Publications: http://www-csli.stanford.edu/publications, Stanford, CA.

Bond, Oliver and Marina Chumakina. to appear. Agreement in Archi: an Overview. In O. Bond, G. Corbett, and M. Chumakina, eds., Archi: complexities of agreement in cross-theoretical perspective, pages XX-XX. Oxford: Oxford University Press.

Bond, Oliver and Marina Chumakina. to appear. Attributives in Archi: a mixed category with multiple bases. Manuscript, University of Surrey page XXXXX. 
Borjars, Kersti and John Payne. 2013. Dimensions of variation in the expression of functional features: Modelling definiteness in LFG. In M. Butt and T. H. King, eds., Proceedings of the LFG13 Conference, University of Debrecen, Hungary, pages 152-170. Stanford, CA: CSLI Publications.

Bresnan, Joan. 2001. Lexical Functional Syntax. Oxford: Blackwell.

Chumakina, Marina. 2012. Periphrasis in Archi. In M. Chumakina and G. Corbett, eds., Periphrasis. The Role of Syntax and Morphology in Paradigms: Proceedings of the British Academy, vol. 180, pages 27-52. Oxford University Press/British Academy.

Comrie, Bernard, Diana Forker, and Zaira Khalilova. 2013. Alignment typology, reflexives and reciprocals in Tsezic languages. In C. Cathcart, S. Kang, and C. S. Sandy, eds., Proceedings of the 37th Annual Meeting of the Berkeley Linguistics Society: Special Session on Languages of the Caucasus, pages 32-51. Wiley.

Creissels, Denis. 2006. Person agreement in Akhvakh: functional motivation and origin of an uncommon type of agreement pattern. revised version of paper presented at RARA and RARISSIMA, Leipzig, 2006.

Dalrymple, Mary. 2001. Lexical Functional Grammar. San Diego, CA: Academic Press.

Dalrymple, Mary and Bozhil Hristov. 2010. Agreement Patterns and Coordination in Lexical Functional Grammar. In M. Butt and T. H. King, eds., Proceedings of the LFG10 Conference, pages 186-206. CSLI Publications: http://www-csli.stanford.edu/publications, Stanford, CA: CSLI Publications.

Dalrymple, Mary and Ronald M. Kaplan. 2000. Feature indeterminacy and feature resolution. Language 76(4):759-798.

Dalrymple, Mary and Irina Nikolaeva. 2006. Syntax of natural and accidental coordination. Language 82-4:824-849.

Dalrymple, Mary and Irina Nikolaeva. 2011. Objects and Information Structure. Cambridge University Press.

Falk, Yehuda. 2006a. On the Representation of Case and Agreement. In M. Butt and T. H. King, eds., Proceedings of the LFG06 Conference. Stanford, CA: CSLI Publications: http://www-csli.stanford.edu/publications.

Falk, Yehuda. 2006b. Subjects and Universal Grammar. An explanatory theory. Cambridge, UK: Cambridge University Press.

Falk, Yehuda N. 2008. Functional relations in the English auxiliary system. Linguistics 46/4:861-889. 
Forker, Diana. to appear. Ergativity in Nakh-Daghestanian languages. In J. Coon, D. Massam, and L. Travis, eds., The Oxford Handbook of Ergativity, pages X-XX. Oxford: Oxford University Press.

Gagliardi, Annie, Michael Goncalves, Maria Polinsky, and Nina Radkevich. 2014. The biabsolutive construction in Lak and Tsez. Lingua 150:137-170.

Hristov, Bozhil. 2013. Defacing Agreement. In M. Butt and T. H. King, eds., Proceedings of the LFG13 Conference, University of Debrecen, Hungary, pages 335-355. Stanford, CA: CSLI Publications.

King, Tracy Holloway and Mary Dalrymple. 2004. Determiner agreement and noun conjunction. Journal of Linguistics 40(1):69-104.

Kuhn, Jonas and Louisa Sadler. 2007. Single Conjunct Agreement and the formal treatment of coordination in LFG. In M. Butt and T. H. King, eds., Proceedings of the LFG07 Conference, pages 302-322. CSLI Publications: http://www-csli.stanford.edu/publications, Stanford, CA.

Manning, Christopher D. 1996. Ergativity: Argument Structure and Grammatical Relations. Dissertations in Linguistics. Stanford, CA: CSLI.

Nichols, Johanna. 2008. Case in Ingush Syntax. In G. G. Corbett and M. Noonan, eds., Case and grammatical relations, pages 57-74. John Benjamins.

Sadler, Louisa. 1999. Non-distributive features and coordination in Welsh. In M. Butt and T. H. King, eds., Proceedings of the LFG99 Conference. CSLI Publications: http://www-csli.stanford.edu/publications.

van den Berg, Helma. 2005. The East Caucasian language family. Lingua $115: 147-190$

Wechsler, Stephen and Larisa Zlatić. 2000. A Theory of Agreement and its application to Serbo-Croatian. Language 76(4):759-798.

Wechsler, Stephen and Larisa Zlatić. 2003. The Many Faces of Agreement. Stanford, CA: CSLI Publications. 